\title{
RESUMEN DEL ACUERDO DE PAZ
}

Jorge Orlando Melo*

$\mathrm{E}$ 1 documento firmado el 26 de septiembre es ante todo un acuerdo por el cual las FARC renuncian a su proyecto, esbozado desde 1962, de llegar al poder por medio de las armas, y aceptan seguir las reglas de la democracia colombiana para buscar sus objetivos políticos.

$\mathrm{E} 1$ gobierno, por su parte, renuncia a imponer a los rebeldes los castigos definidos por la ley penal para sus delitos políticos, conexos o de otro tipo, y se transa por un conjunto de sanciones que permita a los miembros de las FARC actuar legalmente en política: sanciones breves y que no impliquen, por regla general, la pérdida de los derechos políticos para los dirigentes de la guerrilla.

En este sentido, el éxito del acuerdo está dado por el fin de las FARC como organización armada y su transformación en un partido que se somete a las normas legales y que se beneficia de algunos apoyos especiales para actuar.

En el contexto legal internacional actual, es imposible ofrecer a los miembros de las FARC una amnistía tan amplia como la que se dio al M- I 9: es preciso mostrar a la comunidad internacional que los delitos de guerra y de lesa humanidad no quedaron impunes y que los derechos de las víctimas a la justicia han sido satisfechos, al menos en algún grado aceptable, para evitar el riesgo de que el acuerdo sea demandado con éxito ante la Corte Penal Internacional y otras instancias. Esto lleva al sistema de justicia "transicional" que se describe más adelante, y a la búsqueda de una refrendación ciudadana

\footnotetext{
* Ex director del iepri de la Universidad Nacional de Colombia y de la Biblioteca Luis Ángel Arango, [jmelogo@yahoo.com]. Fecha de recepción: 29-09-2016, fecha de aceptación: 20-10-2016. Sugerencia de citación: Melo, J. O. "Resumen del acuerdo de paz", Revista de Economía Institucional 18, 35, 2016, pp. 319-337. DOI: http://dx.doi.org/10.18601/01245996.v18n35.19.
} 
del acuerdo: si el sistema tiene la sanción de los electores, se puede argumentar que cuenta en principio con la aceptación de las víctimas.

Dados los antecedentes de violencia contra la Unión Patriótica, el partido creado por las FARC en 1985, en medio de una negociación anterior de paz, y miles de cuyos miembros fueron asesinados en los años siguientes, el acuerdo se esfuerza por establecer mecanismos para garantizar la seguridad de los guerrilleros que se desarmen y de los miembros del nuevo partido político.

Por último, aunque el acuerdo parte de la idea de que la negociación es para lograr el abandono de las armas y el fin del conflicto armado, y de que la transformación que el país requiera debe ser el resultado de la confrontación política pacífica dentro de las reglas democráticas, aborda dos temas especiales por la relación muy estrecha que han tenido con el conflicto armado en las últimas décadas: el problema de la tierra y el del tráfico de drogas.

\section{LA RENUNCIA A LA LUCHA ARMADA Y LA PARTICIPACIÓN EN LA POLÍTICA DEMOCRÁTICA}

El acuerdo establece que, en un máximo de 180 días a partir de su entrada en vigencia, las FARC entregarán las armas y buscarán promover sus ideas mediante la participación electoral y el debate democrático. Esto requiere:

1. La entrega de todas las armas de las FARC a representantes de las Naciones Unidas.

2. La definición de la condición penal de los guerrilleros, mediante una ley de amnistía, cuyos elementos centrales se resumen más adelante.

3. La formación de un nuevo partido político. Este partido contará con algunas condiciones favorables para su acción:

a. Entre 2018 y 2026 tendrá un mínimo de 5 senadores y 5 representantes, no importa qué proporción de votantes lo favorezcan. Si los votos recibidos permiten un número mayor de elegidos, esto no se tendrá en cuenta. Además, se crearán 16 circunscripciones temporales, vigentes durante los mismos años, para la Cámara de Representantes, en zonas donde el conflicto fue más fuerte. Como en estas zonas las FARC tuvieron influencia notable, es posible que puedan aprovechar estos antecedentes para lograr una representación proporcional elevada, pero otros movimientos pueden competir por estas curules, siempre que no participen en la circunscripción regional ordinaria. Esto quiere decir que normalmente los partidos tradicionales (liberales, conservadores, bloque democrático, cambio radical) no 
pueden participar, a menos que se camuflen en alianzas nuevas. Los electores en estas circunscripciones tendrán un derecho doble a elegir y el único partido que podría participar en ambas circunscripciones, parece, sería el nuevo partido.

b. El nuevo partido solo podrá funcionar después de que se haya concluido el desarme de las Farc. Durante el periodo de entrega de las armas las FARC no podrán actuar en política. Como hay temores de que no tenga un apoyo popular muy alto, entre 2018 y 2026 no se requerirá, para que conserve su personería jurídica, que pase el umbral electoral requerido a los demás partidos. Y durante estos años tendrá un tratamiento favorable para garantizarse acceso a medios de comunicación y recursos económicos para su funcionamiento: recibirá al menos el 10\% del subsidio estatal a los partidos políticos.

c. El acuerdo incluye un amplio abanico de reglas y organismos que buscan garantizar la seguridad de los antiguos guerrilleros y de los miembros del nuevo partido político.

d. El acuerdo incluye una serie de compromisos orientados a hacer más equitativo el sistema de representación política y más fácil el ejercicio político de los partidos menores y de oposición. Entre las principales medidas a las que se compromete el Estado se encuentran la adopción de un nuevo estatuto de la oposición, la reforma electoral, la adopción de mecanismos y tribunales para reducir el fraude en los sitios de mayor riesgo.

\section{AMNISTÍA Y JUSTICIA}

E1 acuerdo busca encontrar un punto medio entre la exigencia de castigo a los miembros de las FARC, reforzada por nuevos compromisos internacionales, y la necesidad de conceder una amnistía amplia a cambio de la renuncia a la lucha armada. Para ello se apoya en los recientes argumentos acerca de la "justicia transicional" y busca satisfacer las exigencias mínimas previstas por los organismos y cortes internacionales, las cuales reiteran la necesidad de dar a las víctimas de la guerra o el conflicto una satisfacción mínima en tres aspectos: que sepan qué ocurrió (verdad), que haya un castigo mínimo aceptable (justicia) y que haya formas de compensación, moral o material, para las víctimas (reparación). En este caso, el acuerdo admite -y este es un elemento muy importante de su estructura y su lenguaje- que en el caso colombiano las personas fueron víctimas tanto de la guerrilla como del Estado y de los organismos paramilitares, promovidos por civiles para enfrentar a la guerrilla pero frecuentemente apoyados por miembros o agentes del gobierno. Así, cuando la guerrilla rechaza el 
uso de la fuerza para imponer las ideas políticas o pide el castigo a los victimarios, puede dirigirse ante todo a los paramilitares o a los agentes del Estado que cometieron delitos, aunque lo que censure pueda haber sido hecho también por la guerrilla. Muchos de los textos del acuerdo están orientados a mostrar que no se incurre en las causales señaladas por las cortes internacionales para controvertir las amnistías aprobadas en acuerdos previos de paz en otros países. En concreto, los acuerdos establecen:

1. Habrá una Comisión para el Esclarecimiento de la Verdad, la Convivencia y la No Repetición, integrada por 11 personas, que funcionará por tres años, oirá en forma pública las declaraciones de los responsables de los hechos y hará un informe.

2. Habrá una Jurisdicción Especial de Paz (JEP), cuyo tribunal más alto estará compuesto por 24 magistrados, seis de ellos extranjeros, para juzgar a los responsables por hechos relacionados con el conflicto. Estará apoyada por una Unidad de Investigación y Acusación, una especie de Fiscalía para la JeP. Habrá amnistía plena por los delitos políticos y conexos, según lo determine la ley que apruebe el Congreso si se refrenda el plebiscito, y que en el proyecto anexo a los acuerdos amplía las definiciones actuales de conexidad. Pero no habrá amnistía para los delitos de lesa humanidad y los crímenes de guerra. En general se adoptan las definiciones normales sobre estos delitos, que incluyen el secuestro, el reclutamiento de menores, la toma de rehenes, las acciones militares contra objetivos civiles, la tortura, la violencia sexual, la desaparición forzosa, etc., pero los textos abren el campo a posibles controversias, sobre todo por la sugerencia reiterada, aplicada en el texto ante todo al narcotráfico, de que los delitos cometidos para obtener recursos para la guerra son por definición conexos. Algunos podrán intentar ampliar esta definición al secuestro extorsivo y no solo, como ya se dice en el acuerdo, a la captura de combatientes en "acciones militares", que probablemente incluye la captura de rehenes militares en una "emboscada". Seguramente se presentarán controversias sobre acciones orientadas por una lógica militar, que no tienen en cuenta razonablemente el alto riesgo para los civiles, como el uso de cilindros bombas o el minado de vías.

3. Los delitos de lesa humanidad y de guerra tendrán diferentes tipos de sanción. Esta será aplicada por el sistema de justicia transicional si el acusado hace una declaración verdadera de los hechos, es decir, si contribuye sin reticencias al establecimiento de la verdad para las víctimas. Las sanciones del sistema de la JEP consisten en restricciones temporales a la libertad de movimiento (una especie de 
“libertad condicional” dentro de un área limitada, donde quienes las reciban realicen tareas sociales), a las que se suman obligaciones de trabajo comunitario o social y de apoyo a los objetivos del acuerdo, como el desminado (o para decirlo en el lenguaje eufemístico que a veces se emplea en el acuerdo, a "la limpieza y descontaminación de municiones sin explotar"), o la siembra de cultivos legales. Las personas sancionadas por la JEP en los casos a y b siguientes no pierden sus derechos políticos, y este es un punto central en la aplicación de los acuerdos.

a. Si la participación en esos delitos fue secundaria o en obediencia de órdenes del mando guerrillero (o militar), habrá una sanción de 2 a 5 años. (Esto podría incluir, por ejemplo, a los miembros de un grupo que hizo un secuestro o mantuvo vigilados a los secuestrados).

b. Si la participación en estos delitos es directa o decisoria, la sanción es de 5 a 8 años.

c. En los casos en que se pruebe que no hubo una declaración oportuna de verdad (reconocimiento "tardío"), la duración de la sanción es igual, pero se considera que es una sanción ordinaria y puede incluir "privaciones efectivas de la libertad", es decir cárcel o prisión, y parece que los condenados pierden sus derechos políticos mientras cumplen la pena.

4. Para los delitos de lesa humanidad y de guerra en los que no haya reconocimiento y "verdad" las penas pueden ir de 15 a 20 años de prisión. Las implicaciones de esto pueden ser graves: el acusado pierde los beneficios económicos, los derechos políticos y la garantía de no extradición que se aplica a todos los sancionados por la Justicia Transicional.

5. La Justicia Transicional puede ser aplicada, además de a los guerrilleros y los militares -dentro de la ficción adoptada sobre los agentes del "conflicto armado interno"-, a terceros, a particulares que hayan intervenido conformando o financiando grupos de justicia privada o paramilitares y que no se hayan sometido a la Ley de Justicia y Paz. En estos casos, dado que podría llevar a una acción contra un número muy amplio de personas, muchas de ellas con elevado poder económico o social, la responsabilidad se restringe a las que hubieran sido determinantes en las acciones ilegales u organizadores de esos grupos; se excluye, por lo tanto, a los propietarios o empresarios rurales, por ejemplo, que pagaron a esas organizaciones como respuesta a amenazas de estas. Esto, que puede llevar a controversias complejas para probarlo, deja confusa la situación de la mayoría de los contribuyentes, que usualmente estaban amenazados por la guerrilla, no 
participaban en la organización de los grupos, pero los veían con algo de simpatía, incluso si censuraban sus excesos. Sin embargo, es poco probable que el sistema de justicia se mueva contra ellos, excepto en casos muy especiales.

6. Para los casos de personas ya condenadas (lo que es aplicable a guerrilleros ya condenados o a militares sancionados por "falsos positivos" o desapariciones, por ejemplo), el interesado puede pedir la revisión de su caso por la JEP. Esto es también aplicable a civiles condenados por apoyo a organizaciones armadas privadas. En estos casos, parece que solo es posible una reducción de la pena actual.

7. Para la determinación de responsabilidades se acepta que en principio los comandantes de las FARC presenten la lista de los miembros y los hechos de los que se hacen responsables. Esto puede servir para evitar incongruencias, o que en una nueva declaración "personal" salgan a la luz hechos que incriminen a alguien por algo que no dijo, y podría llevar a que solo se tengan en cuenta los hechos que los dirigentes de las FARC quieran presentar. Sin embargo, se requiere que esta información se confirme mediante una presentación personal, y esto puede llevar a un sistema que cumpla mejor con la intención de que las víctimas de las FARC reciban información verdadera de lo que pasó con sus deudos.

8. Dada la importancia que se da a la lucha contra los grupos paramilitares, se crea una "Unidad Especial de investigación para el desmantelamiento de las organizaciones criminales responsables de homicidios y masacres o que atentan contra defensores/as de derechos humanos, movimientos sociales o movimientos políticos, incluyendo las organizaciones criminales que hayan sido denominadas como sucesoras del paramilitarismo y sus redes de apoyo, y para la persecución de las conductas criminales que amenacen la implementación de los acuerdos y la construcción de la paz".

\section{REFORMA AGRARIA INTEGRAL}

El acuerdo, que acepta la argumentación convencional y muy discutible de que el conflicto armado ha sido en gran parte provocado por el problema de la tierra, establece el compromiso del gobierno de poner en marcha un programa de reforma agraria integral. En la práctica, es una propuesta más bien moderada, menos ambiciosa que la reforma agraria aprobada en 1967, que se concentra en la distribución de tierras en el dominio público y en el desarrollo de programas complementarios de desarrollo rural. Incluye fundamentalmente: 
1.Usar el Fondo de Tierras, integrado por las propiedades que han revertido al Estado por diferentes tipos de extinción de dominio (delitos, ilegalidades en su adquisición, ausencia de explotación por el periodo mínimo legal), para conformar fincas campesinas. E1 acuerdo habla de que hay 3 millones de hectáreas disponibles, lo que es dudoso, pues muchas de esas tierras se encuentran en medio de largos y difíciles procesos. A esto se añadirían, como ya es posible, expropiaciones y compras, áreas recortadas a las zonas de reserva natural y, por supuesto, los baldíos en zonas aptas para cultivos campesinos.

2. Dar subsidio o crédito para la adquisición de propiedades campesinas por compra. En este aspecto, el país ha sido totalmente discriminatorio: dio, a partir de 1991, más de un millón de subsidios para la compra de viviendas para sectores populares urbanos y no puso en práctica real, aunque lo aprobó, un sistema similar para conformar propiedades campesinas. Si en los próximos cinco años se logran crear, con un subsidio parcial -el acuerdo habla de "subsidio integral"-, 100.000 fincas de 10 hectáreas en promedio, esto requeriría un millón de hectáreas y recursos muy inferiores a los empleados en el programa de vivienda gratuita, y podría ser la base para un nuevo lanzamiento de la economía campesina en Colombia.

3. Expedir títulos plenos de propiedad a 7 millones de hectáreas que son hoy, según cifras imprecisas, posesiones informales.

4. Hacer un catastro rural de calidad. Esto, que está aprobado en la ley hace al menos 150 años, busca al mismo tiempo formalizar los títulos rurales y ser base para un buen sistema de impuesto predial rural, con impuestos más progresivos que los actuales (hoy el predial tiene progresividad entre el 4 y el 10 por mil).

5. Cerrar la frontera agraria. (También en este caso la ley, desde hace más de 20 años, decretó su cierre).

6. Poner en marcha programas complementarios como los que se promovieron siempre en las leyes anteriores de reforma agraria y han hecho parte de la retórica y de los proyectos de desarrollo de casi todos los gobiernos a partir de 1958: crédito, mercadeo, infraestructura, educación, salud, asistencia técnica, alimentación apropiada, etc. (Como subrayó Álvaro Gómez Hurtado para frenar la distribución de tierras, la reforma agraria no podía limitarse a dar tierra: tenía que incluir todos estos aspectos).

7. Los acuerdos agrarios pueden crear grandes expectativas en relación con la aplicación local de los diversos planes de desarrollo convenidos, y en particular dudas sobre las normas vigentes en las zonas de reserva campesinas y en las zonas donde se apliquen los 
planes de acción local o regional, así como sobre los poderes de las comunidades y de los organismos creados para tomar decisiones obligatorias. En general, parece que los acuerdos no crean condiciones nuevas de aplicación de la ley en estos sitios, y la aplicación de los diversos planes dependerá de las reglas legales generales: aunque la consulta a las comunidades se menciona en muchos casos, no parece tener el efecto de la consulta a las comunidades establecida en relación, por ejemplo, con proyectos de minería en zonas indígenas. El punto en el que adquiere mayor peso es en el de la substitución de cultivos ilícitos, pero aun en ese caso la opinión de los consultados no es de cumplimiento obligatorio.

\section{EL NARCOTRÁFICO}

$\mathrm{E} 1$ acuerdo, en textos llenos de eufemismos, establece el compromiso de las FARC de contribuir "de manera efectiva" y de diferentes formas para la solución definitiva a este problema, pero no hay compromisos específicos ni obligaciones claras de dar información sobre procesamiento o comercialización.

E1 gobierno se compromete a "poner en marcha" "políticas y programas" para enfrentar la corrupción producida por la droga, etc. Entre otras cosas se compromete a perseguir el narcotráfico (p. 109) y el lavado de activos, al control de insumos, a la extinción de dominio (una "nueva estrategia de política criminal" que incluye "articular instancias", un uso más "eficiente de los recursos", la formulación de un nuevo estatuto" contra el lavado de activos y el control de la importación y comercialización de insumos para la producción de drogas").

Lo fundamental, que simplemente reitera las políticas actuales, es el compromiso de tratar el consumo como un tema de salud, lo que en términos generales ya es aceptado en el país, y erradicar los cultivos en forma voluntaria, aunque si esto no se logra o las comunidades se oponen, podrá haber erradicación manual. Los cultivadores campesinos no serán castigados penalmente, lo que de hecho ya ocurre y es parte de cualquier política sensata contra la droga, que debe centrarse en la represión del tráfico y del procesamiento.

\section{COMPROMISOS VARIOS}

Los acuerdos incluyen decenas de compromisos menores sobre diferentes aspectos de la acción pública. En particular, vale la pena destacar que muestran una confianza muy alta en la eficacia de la ley y la Constitución, en la capacidad de las burocracias estatales, en el 
impacto de un lenguaje incluyente y políticamente correcto, todo lo cual puede considerarse, a la luz de la historia de las FARC, como una señal clara de su incorporación en la lógica y la retórica de la acción política colombiana. Por otra parte, resulta clara la importancia que dan los acuerdos a la formulación de planes de diverso alcance y contenido. Hay planes decenales, cuatrienales, anuales, nacionales, locales, regionales, relativos a muy diferentes aspectos. En total, identifiqué al menos 32 planes pactados, la mayoría de los cuales requieren comisiones, equipos, instituciones nuevas e instancias diversas para su formulación y aplicación. ¡Bienvenidos a la democracia, al papeleo y a la burocracia!

\section{LA VIGENCIA LEGAL Y CONSTITUCIONAL DEL ACUERDO}

El acuerdo incluía normas fuertes para garantizar su eficacia legal: la de que se firmaría como un Acuerdo Especial a la luz de los Convenios de Ginebra (pp. 176 y 249: la interpretación del efecto de esto parece excesiva), para que su contenido hiciera parte del llamado "bloque de constitucionalidad", la que pactaba una reforma constitucional para incluir el acuerdo "íntegramente" en la Constitución y la que señalaba que si era refrendado con el voto favorable de al menos un $13 \%$ del censo electoral se volvería parte del orden legal mediante una ley aprobatoria, votada en conjunto y con un control constitucional único.

La sentencia de la Corte, que definió que la refrendación popular del acuerdo mediante el plebiscito tiene un valor político, que los contenidos del acuerdo no se incorporan al orden legal en forma automática, que el plebiscito no tiene capacidad para modificar la constitución y que obliga exclusivamente al Presidente de la $\mathrm{Re}$ pública, abre nuevas posibilidades para su desarrollo: según esto, el Congreso podrá modular -aunque sin violar el espíritu del mandato político popular- los acuerdos, incluso modificando algunas reglas establecidas, si considera que son contrarias a la Constitución o son inconvenientes o injustas.

En caso de que el acuerdo no sea refrendado, el impacto legal más grave parece ser la caída del Acto Legislativo para la Paz, de 2016. En esa circunstancia, aunque legalmente el presidente podría firmar un nuevo acuerdo, si las FARC están dispuestas a reiniciar negociaciones en forma inmediata para renunciar a mucho de lo conquistado, los mecanismos legales para ponerlo en práctica volverían a la norma usual, al quedar sin vigencia el sistema de trámite rápido de leyes y reformas constitucionales, los poderes especiales al presidente, etc. Esto haría casi imposible toda negociación en el resto del actual pe- 
riodo presidencial y convertiría las elecciones de 2018 en un nuevo plebiscito sobre las reglas para una nueva negociación futura.

\section{EL DESARROLLO PRÁCTICO DE LOS COMPROMISOS}

Aunque se hizo una minuciosa definición de los numerosos compromisos y detalles de procedimiento, quizá con el fin de garantizar al máximo el cumplimiento de parte y parte, todo estará sometido a la normal rutina del sistema administrativo público. Sin embargo, lo fundamental es el abandono de la lucha armada por parte de las FARC, y la contraprestación central, la amnistía para delitos políticos y conexos y las penas alternativas para crímenes de guerra y de lesa humanidad. Esto probablemente se cumpla de manera razonable y rápida, tanto por la forma cuidadosa como ha sido diseñado el proceso como por la evidente voluntad política mutua de ponerlo en práctica. Si es así, el acuerdo habrá logrado su fin principal: eliminar la guerrilla más fuerte, que ha durado más de medio siglo, abriendo el camino para que sus miembros vuelvan a la acción política legal. Los efectos de esto sobre la sociedad colombiana serán muy grandes, y en principio muy positivos, aunque no se resuelvan del todo los problemas y se mantengan los factores tradicionales de violencia. La idea de que para vivir en paz razonable hay que resolver todos los problemas graves del país (como decía el M-19 hace más de 20 años, si hay hambre o hay pobreza no hay paz) o de que se debe sancionar a todos los culpables, haría imposible cualquier acuerdo de paz por décadas.

En términos de vigencia y cronograma, lo esencial en caso de que se aprobase el plebiscito es lo siguiente:

1. Así no esté expreso en forma clara en el texto, el acuerdo entraría en vigencia con dicha aprobación, en desarrollo del acto legislativo de 2016. Esto define, por lo tanto, el 2 de octubre como día D, a partir del cual se adopta un cronograma detallado, pese a que en los textos parece establecerse que ese día es el de la "firma del Acuerdo Final". Probablemente la Ley de Amnistía y la prohibición constitucional de extradición que se pactó cubran los delitos hasta esta fecha, de modo que los delitos cometidos después de ella serán de competencia de la fiscalía, aunque es posible que cuando se firme el "Acuerdo Final" se señale la fecha para ello.

2. Al día siguiente de la entrada en vigencia del acuerdo, el gobierno debe presentar al Congreso el proyecto de Ley de Amnistía y el Acto Legislativo para la creación de la JEP. Ese mismo día comienza el desplazamiento a las zonas de agrupación de los guerrilleros, previa suspensión de las órdenes de captura que pueda haber contra ellos. 
3. Ese mismo día se crea el Consejo Nacional de Reincorporación, de 4 miembros (p. 65); se pone en marcha el Consejo Nacional para la Reconciliación y la Convivencia (p. 41) y se crea la "Comisión de Implementación, Seguimiento y Verificación del Acuerdo y de Resolución de Diferencias", de 6 miembros (p. 83).

4. En el momento de "entrada en vigor" del acuerdo, la agrupación promotora del nuevo partido político designa tres voceros en el Senado y tres en la Cámara.

5. Antes del 11 de octubre, el gobierno presenta a la Comisión de Implementación, Seguimiento y Verificación del Acuerdo y de Resolución de Diferencias una lista de las medidas de desarrollo temprano.

6. E1 proceso de cese al fuego y desarme (“dejación de armas") se cumple en 180 días, y esto lleva a la constitución del nuevo partido, que se registrará al término de este proceso.

\section{ANEXO}

1. Algunos nudos, riesgos y problemas:

a. Justicia

i. Hay amnistía para delitos políticos, sanción "alternativa" para delitos de lesa humanidad y de guerra (incluidos secuestro, reclutamiento de menores, uso de minas antipersonales, que no pueden ser amnistiados según el derecho internacional).

ii. Se mantienen los derechos políticos a los culpables de delitos graves, siempre que hayan hecho una declaración integral que satisfaga la obligación de verdad.

iii. Hay inquietudes por la posible sanción a empresas y particulares por apoyo a paramilitares. El acuerdo dice que si fueron obligados o lo hicieron por amenazas (¿de los paras?) no hay sanción: solo si tuvieron un papel central o determinante en la organización. Esto deja de lado la mayoría de los casos: los que pagaban de gusto, porque estaban amenazados por la guerrilla, pero no eran organizadores ni promotores.

b. Aplicación de justicia internacional: la Corte Internacional de Justicia puede juzgar a personas que hayan sido amnistiadas o condenadas a penas irrisorias (los crímenes de guerra y de lesa humanidad son imprescriptibles y no son amnistiables, oNU, 1968). En teoría, podrían considerarse irrisorias penas de "restricción de la libertad de movimiento" por 5 a 8 años sin cárcel, para culpables de violaciones, secuestros o ataques como el de Bojayá, con centenares de víctimas civiles. Sin embargo: 
i. Políticamente, es poco probable que haya una decisión de un organismo internacional contra el acuerdo. Los amnistiados son en general rebeldes (no militares que se auto amnistían), hay gestos de "verdad", reparación o "compensación a las víctimas", acuerdo de entidades que aparecen como representantes o voceros de las "víctimas" y una sanción, así sea leve, en casos de responsabilidad individual comprobada por crímenes de lesa humanidad o de guerra. Y la aprobación por plebiscito puede ser interpretada como compartida por las víctimas... (en Colombia todos somos víctimas). (En 2002 Colombia se unió al Tratado de Roma, pero el gobierno de Pastrana aplazó su vigencia por siete años, en principio para poder sancionar con menos rigor a la guerrilla en caso de un acuerdo. El acuerdo, en la realidad, se hizo con los paramilitares en 2005, sin amnistía pero con penas muy bajas). Pero no se ha sancionado a Colombia por imponer castigos irrisorios a autores de centenares de homicidios como los paramilitares. Y dados los argumentos admitidos en las cortes colombianas, la vigencia aplazada del Tratado de Roma no eximía al gobierno de las obligaciones del DIH, que ya habían sido definidas como parte del "bloque de constitucionalidad", aun sin tratados concretos, por la Corte Constitucional colombiana (2002, Sent. C-225).

ii. Si hay información muy amplia de los hechos, es decir una contribución importante a la verdad, y el proceso comienza a parecer serio ( $\sin$ listas de delitos confeccionadas por los jefes), ninguna corte interferirá en un proceso que dé a las víctimas información decisiva sobre el estado de sus deudos, sus restos, los responsables, etc.

iii. Hay problemas con delitos concretos. Se amnistían los delitos políticos y conexos. Esto incluye el narcotráfico, excepto si fue para lucro personal. El secuestro sería delito conexo, por la definición genérica de conexos de los delitos cometidos para conseguir fondos para la guerra, pero no sería amnistiable por ser de lesa humanidad, al menos si no fue el resultado de una captura de un combatiente en una operación militar.

2. Lógica del acuerdo

a. Es un acuerdo en el que las FARc, en los hechos, con su conducta real, aceptan que su proyecto político fracasó: transformar el país y establecer una sociedad justa mediante la lucha armada. Las FARC dejan de existir como guerrilla y se transforman en un partido político que acepta las reglas de la democracia. Es decir, en cierto modo, vuelven a donde estaban en 1958-1962: a una sociedad donde existe una democracia, llena de limitaciones, pero ahora aceptando sus reglas y buscando ampliarla, en vez de destruirla como una "demo- 
cracia burguesa" o falsa. Pero es difícil reconocerlo, y las FARC buscan una justificación histórica, un relato que presente la lucha armada no como el resultado de una concepción política e ideológica sino como la respuesta inexorable e inevitable a la violencia política, social y económica del sistema.

b. Según la versión de las FARC, ante la violencia arbitraria del establecimiento, que en 1964 atacó a los campesinos de Marquetalia, que tenían organizaciones armadas de autodefensa, y ante las injusticias sociales y las limitaciones democráticas, la respuesta armada era inevitable. Esto es insuficiente, por supuesto, y no explica por qué en Colombia la guerrilla pudo adquirir tanto poder y vivir casi 60 años, cuando en los países vecinos, con pobreza e injusticia similares y menos democracia, la izquierda buscó el poder ampliando la democracia y no con las armas, y muchas veces llegó al poder. Y no tiene en cuenta la consecuencia de la decisión de responder a esas injusticias con las armas: la reacción cada vez más violenta, primero con acciones ilegales del Estado (1978) y después con la formación de grupos civiles armados para destruir la guerrilla y a sus simpatizantes. Colombia, como resultado de la decisión de buscar la justicia con fusiles, es más pobre, más injusta y quizá más autoritaria y hostil a las políticas populares de lo que habría sido con una izquierda legal, que fue destruida de hecho como consecuencia de la guerra.

c. La guerrilla colombiana no creció y se fortaleció porque la población le diera un apoyo amplio. Su crecimiento depende de varios factores, entre los cuales son muy importantes: a) la existencia de una tradición local de guerrilla, que permitió a algunos grupos vincularse a sitios con una historia de conflicto social y apoyarse en la experiencia real de campesinos armados, lo que le dio ventajas tácticas sobre los militares, desconocedores del terreno por décadas; y b) el hecho de que, incapaz de desarrollar una política proporcionada y legal de freno a la guerrilla, varios gobiernos toleraron una acción militar ilegal, que incluyó la tortura, las ejecuciones ilegales y la desaparición de simpatizantes de la guerrilla. Esto le dio un aire de heroicidad y martirio, y la convirtió en una víctima clara de la injusticia oficial, sobre todo desde 1979, lo cual llevó a que los gobiernos posteriores, de 1982 a 2002, buscaran una solución negociada a la guerra: estos esfuerzos de negociación dividieron a los grupos dirigentes, y los sectores hostiles a la negociación, usualmente más débiles en lo que llaman "el bloque de poder" o "las clases dirigentes" o "las élites", apoyaron las acciones ilegales. Por otra parte, la guerrilla, sin apoyo social, se financió desde el comienzo con ataques a civiles, secuestros y extorsiones. Esto le 
permitió sobrevivir con dificultades hasta 1980, pero en las dos últimas décadas del siglo xx el narcotráfico se convirtió en principal fuente de sus recursos, y explica su gran crecimiento militar.

d. La insistencia en la justicia de la rebelión, en el derecho a la insurrección, hace imposible que las FARC, así lo hagan en los hechos, acepten en forma expresa que su proyecto armado fracasó. Por eso, aunque en forma vaga han pedido perdón por los sufrimientos causados a las víctimas, pedir perdón al país por el error político e histórico de buscar el triunfo político por medio de las armas es muy difícil, y condenan el uso de las armas en un sentido genérico, como si se refirieran exclusivamente a los paramilitares, que siguieron su ejemplo. Pero esto no tiene mucha importancia si abandonan, de hecho, la lucha armada: en este caso los hechos son más fuertes que las palabras.

e. Por lo tanto, estando derrotados, y con un ejército que en gran parte ha sido reclutado en las últimas décadas por motivos económicos, y sin formación política previa, los jefes buscan una salida honorable, pues ya desperdiciaron su segunda oportunidad de negociar y no habrá nuevas oportunidades en un plazo razonable. La salida honorable incluye: en los hechos, un tratamiento favorable, económico y penal, para todos, y un tratamiento político favorable para los jefes, que podrán ir al Congreso y pronunciar discursos durante ocho años, culminando su carrera en forma digna. En el plano simbólico, el acuerdo no cuestiona las justificaciones de las FARC y les hace concesiones verbales importantes:

i. La violencia es sobre todo del sistema y los paramilitares.

ii. Acepta los proyectos "reformistas" de las FARC en relación con el campo, y el argumento "comunitario" sobre los cultivos de droga.

f. En la realidad, el gobierno les hace pocas concesiones efectivas, excepto en justicia, pero esto parece realista: no habrá paz si la condición es encarcelar a los jefes de las FARC y ninguna renegociación podría lograr su aceptación.

3. Comparación con acuerdos anteriores

La amnistía de 1982-1983 primero fue sin desarme y sin excluir ningún delito, muchos guerrilleros presos eran liberales y retomaron las armas en forma inmediata. En 1990 la amnistía al M-19 fue total, sin ninguna obligación de verdad, y sin límites por tipos de delitos. Ahora se deben confesar y aclarar hechos serios. Y hay pérdida de beneficios por declaraciones tardías o que no contengan toda la verdad.

En los acuerdos anteriores no se tuvo en cuenta, ni en la realidad ni en la retórica, a las víctimas, ahora centrales en la retórica e im- 
portantes en muchos proyectos de ayuda. Fuera de la compensación moral que da el saber que las FARC se han rendido de hecho, y del valor de la información sobre los deudos, habrá indemnizaciones y programas sociales, seguramente muy burocráticos y discutibles. E1 sueño de que las FARC indemnicen a sus víctimas (p. ej., que devuelvan lo que recibieron por secuestros) es de remoto cumplimiento. La información precisa de sus recursos, las decenas de declaraciones oficiales sobre lo que se les capturó entre 2002 y 2014 hacen pensar que no tienen grandes acumulaciones de dinero, ni en efectivo (caletas) ni en depósitos bancarios, ni la capacidad administrativa para manejar con seguridad grandes inversiones y recursos: quizá el dinero que conseguían se gastaba sobre la marcha y lo que no se gastaba acababa apropiado por tesoreros y "responsables de finanzas". Sorprende que, pese al gran número de "responsables de finanzas" que se entregaron o fueron capturados en esos años, no se sepa mucho acerca de cómo manejaban sus recursos, y que las declaraciones de que poseen centenares de miles de hectáreas se hayan desmoronado y convertido apenas en algunas fincas más o menos grandes de algunos jefes. De modo que la reparación material a las víctimas provendrá casi toda de los impuestos que pagamos, como pasa siempre (así ocurre también con la reparación a las víctimas de errores judiciales y de los organismos de control: todos pagaremos las indemnizaciones por la sentencia del procurador Ordóñez contra Piedad Córdoba).

4. Costos

a. En apariencia son muy altos, pero en la práctica son ante todo los costos de proyectos sociales normales del sistema.

b. El subsidio a reinsertados durante el tiempo que se aplicará cuesta menos que el plebiscito del 2 de octubre (que según la Registraduría del Estado Civil cuesta $\$ 300.000$ millones, us $\$ 100$ millones); sostener a 10.000 ex guerrilleros durante 2 años con el $90 \%$ del salario mínimo, junto con el pago inicial de $\$ 8$ millones puede costar unos $\$ 280.000$ millones (us $\$ 95$ millones). Un proyecto social como “Ser pilo paga”, ya en vigencia, subsidiará en 2018 a 40.000 jóvenes con $\$ 20$ millones a cada uno, con un costo de $\$ 800.000$ millones en ese año.

c. Los costos militares y de justicia se mantendrán en general en niveles similares a los actuales, aunque lo razonable a mediano plazo es que disminuyan lentamente y que el país gaste menos que hoy en seguridad, incluida la seguridad privada.

d. Un factor incierto es el de los "milicianos bolivarianos" (grupos armados de apoyo que llevan una vida normal: las milicias del pueblo no son sujetos del acuerdo) y cuanta gente aparezca buscando benefi- 
cios de reinserción. E1 sistema de declaraciones de "verdad" permitiría, con una base de datos exigente, controlar las declaraciones y verificar los datos. Los jefes podrán perder los beneficios por incluir gente falsa en sus listas, lo que podría establecerse por declaraciones posteriores de guerrilleros. Los mecanismos establecidos parecen llevar a un grado de verdad razonable, más de lo que ocurrió con los paramilitares.

5. Realismo y posibilidades de aplicación

a. Inflación retórica, pero sobre todo burocrática. Los grandes sueños sociales y los programas grandiosos terminarán a medias, pero esto no es muy grave, si se cumple lo esencial.

b. Impacto de la sentencia de la Corte: el acuerdo ya no es parte del bloque de constitucionalidad y no entra en la ley: es un hecho político, que debe ser sometido al Congreso como tal. Esto significa que habrá reformas y modificaciones que serán sostenidas por la Corte y que las FARC podrán ver como violaciones del acuerdo. Por supuesto, la energía del presidente para defender los textos originales será clave para aprobar partes del acuerdo como leyes, pero habrá algunas que se enreden. Las normas de justicia y amnistía se podrían aprobar sin cambios importantes, con precisiones sobre algunos delitos, como el secuestro.

c. Proyectos sociales: el punto central es el desarrollo de oportunidades para la pequeña y la mediana propiedad en el campo. Si se establece un sistema amplio de subsidios de compra de propiedad campesina, similar al que existe para vivienda urbana, incluso parcial (una finca campesina vale menos que una vivienda de interés social en la ciudad), puede aliviar en gran medida la presión rural. Esto implica ante todo diseñar modelos combinados, de pequeña y gran propiedad, en zonas como los Llanos y la altillanura, para ubicar algunos miles de nuevos campesinos al lado de las grandes plantaciones.

d. Droga: la relación es tenue y el acuerdo es hueco. La propaganda dice que se resolverá el problema de la droga, pero el fin de las FARC apenas debilita marginalmente un negocio que existe con independencia de las FARC y por razones totalmente diferentes. Algunos de sus miembros se quedarán en ese negocio, pero menos de los que hoy participan. Y el gobierno tendrá más posibilidades de actuar con eficacia para reducir algo el peso de la droga, al no enfrentar un juego político como el de los campesinos movilizados por las FARC y reducir los traficantes a carteles no políticos. La propaganda radial oficial añade que desaparecerá la minería ilegal, sin bases reales, aunque en algunos conflictos las FARC moviliza a los mineros. 
e. Con una aplicación confusa, lenta y burocrática, llena de organismos y gestiones, buena parte de la satisfacción de los guerrilleros en los próximos ocho años dependerá de su incorporación a burocracias sociales marginales, comités, organismos rurales, etc., que el acuerdo crea por decenas. La posibilidad de que el nuevo partido político logre una gran movilización por el incumplimiento de partes del acuerdo no parece muy grande: a pesar de las promesas de leche y miel, la gente no cree que la paz traiga una bonanza económica para todos. $\mathrm{E} 1$ impacto de sus reclamos por el incumplimiento de estas promesas burocráticas no debería ser muy grande.

f. El sueño burocrático aparece ante todo en la idea de hacer por fin un catastro de calidad de la propiedad rural.

g. Es posible que algunos de los guerrilleros sigan dedicados al narcotráfico. Esto no representa un agravamiento, pues muchos saldrán de él. Y cabe pensar que, si la reinserción es ineficaz, algunos se vinculen a grupos de delincuencia existentes. Pero en todo caso, será una parte menor del grupo actual: si 7.000 de los 10.000 abandonan las armas habría una fuerte reducción real de la violencia, la delincuencia, las muertes rurales, etc. La desmovilización de las FARC no elimina otros problemas. El ELN subsiste, con una fuerza que se calcula en 1.500 hombres. Pero para el ejército nacional debe ser más fácil enfrentar a esos 1.500 que a 11.500 , con un ambiente social aún más hostil al proyecto armado que el de hoy. El espacio político del ELN será más limitado, y sus grupos de apoyo ideológico y logístico urbano probablemente se reducirán.

h. Lo que la población espera es ante todo un clima más pacífico y de mayor seguridad individual:

i. En las ciudades, donde las FARC tiene presencia marginal, no se advertirá mucho el cambio. De hecho, desde hace 12 años su presencia es baja, al decaer las milicias, y en los últimos dos años se ha vivido en paz real, aunque subsista el fantasma de la guerra, que siempre pesa en la vida diaria, en las precauciones con los niños, en decenas de gestos ya incorporados a la vida. No hay secuestros en las ciudades hace varios años, ni ataques. En grandes ciudades pueden aparecer algunos ex guerrilleros, si los subsidios no funcionan bien, en bandas menores, y aumentar la delincuencia menor. Pero no es lo más probable: lo más seguro es que los elementos que impulsan la delincuencia urbana se mantengan iguales, y que la capacidad del Estado para enfrentarla algo mejore, de modo que el resultado neto sea una leve disminución del número de homicidios y otros delitos. 
ii. En ciudades pequeñas y zonas de presencia narco y guerrillera puede haber una leve disminución de delincuencia.

iii. En el campo, en zonas con influencia del narcotráfico, el enfrentamiento puede hacerse más intenso por una mayor presencia militar, pero la concentración de la acción del gobierno en estos grupos puede reducir la violencia. La secuencia ataque guerrillero-represión o ataque armado contra campesinos-desplazamiento puede disminuir.

6. La decisión final

a. En términos emocionales, es difícil votar por el “sî". En especial, si implica perdonar a la guerrilla, un perdón que esta ha pedido en forma confusa y titubeante, después de más de 50 años de guerra absurda, de decidir que lucharían contra las injusticias y limitaciones de la democracia usando las armas, con centenares de miles de muertos (muchos de ellos cercanos a sus planteamientos, como los de la UP) y el efecto de anular a la izquierda. Colombia es el país latinoamericano donde más lejos ha estado del poder y más lejos está. Es difícil votar "sí" cuando se oye lo que dicen las FARC: que están llegando a un acuerdo como prueba de su fortaleza, de su capacidad, y no de su debilidad; que representan un proyecto político que tiene respaldo de la población, que los violentos son otros, pero no ellos también. $\mathrm{Y}$ es difícil votar "sî" para que quienes estuvieron al mando de una organización que promovió el secuestro, ataques a pueblos, el uso de minas, de bombas en cilindros de gas, reciban una amnistía y tengan derechos políticos.

b. Pero en términos prácticos, esa amnistía, lo que más irrita, ya la tienen de hecho. El único jefe de las FARC que ha pasado largos años en la cárcel es "Simón Trinidad", y más por el narco que por otros delitos. La posibilidad de sancionarlos es muy reducida.

c. Y la posibilidad de someterlos militarmente existe, pero parece ser más costosa que el acuerdo.

d. Por eso respaldar el acuerdo y votar "sî" parece una fórmula pragmática para reducir los costos de acabar con las FARC como organización armada. Y si pierde mucho peso la justificación de la violencia como forma de acción política, pueden mejorar las condiciones para una política menos violenta: puede fortalecerse y ampliarse el espacio de debate público y de democracia.

e. Votar "sí" al acuerdo no significa perdonar a las FARC, ni sus errores políticos e históricos, que son imperdonables, ni sus crímenes y actos de violencia, que solo pueden perdonar las víctimas directas, cuando, tras oír sus declaraciones y verificar la verdad, decidan si pueden perdonar. Pero, sin usurpar el derecho de las víctimas a perdonar 
si lo desean y lo logran, vale la pena al menos intentar convivir con unas FARC desarmadas, que respeten unas reglas de convivencia y de diálogo. Quizá muchos que apoyan con entusiasmo el acuerdo de paz voten en elecciones futuras contra ellos, aunque compartan algunos de sus objetivos - una sociedad más igualitaria, menos sujeta al dominio de los mercados y del consumo- porque, en vista de su historia, no confían en ellos. Pero si su retorno a la democracia prueba ser real y sincero, tal vez logren hacer parte de proyectos políticos que traigan cambios deseables para el país. 